\title{
Application of Adversarial Risk Analysis Model in Pricing Strategies with Remanufacturing
}

\author{
Liurui Deng ${ }^{1}$, Bolin $\mathrm{Ma}^{2}$ \\ ${ }^{1}$ College of Economics and Management, Hunan Normal University (China) \\ ${ }^{2}$ College of Mathematics and Information Engineering, Jiaxing University (China) \\ 676352990@.qq.com,676406326@qq.com
}

Received: August 2014

Accepted: January 2015

\section{Abstract:}

Purpose: This paper mainly focuses on the application of adversarial risk analysis (ARA) in the pricing strategy with remanufacturing. We hope to obtain more realistic results than classical model. In fact, the classical Stackelberg model believes that since OEMs are the monopoly position, they know the pricing strategy of remanufacturers in the second period. However, the development of remanufacturing industry shakes OEMs' monopoly position and makes remanufacturers become stronger and stronger, so, in fact, OEMs don't know the pricing strategy of remanufacturers in the second period. Hence, the classical Stackelberg model isn't suited for reality. In this paper, we suppose that the OEMs don't know the pricing strategy of remanufacturers and recovery cost and only know their own information. Based on these assumptions, we predict the pricing strategy of remanufacturers from OEMs' point. Furthermore, we build OEMs' own pricing strategy based on the predicted the remanufacturers' pricing strategy, which is called OEMs' 1-order ARA model. Similarly, we look ourselves as remanufacturers and forecast OEMs' pricing strategy. Based on the forecasted OEMs' pricing strategy, we create the remanufacturers' own pricing strategy. Simulated results make us find ARA model gets more profit than classical Stackelberg model.

Design/methodology/approach: In order to gain more actual research, we apply adversarial risk analysis to the pricing strategy with remanufacturing. As OEMs, they don't the recovery cost and the pricing strategy of remanufacturers, so they have to analyze and predict the pricing strategy of remanufacturers and based on this predicted the pricing strategy of remanufacturers 
build their own pricing strategy. The pricing strategy of OEMs is called 1-order ARA model of OEMs. To similar, remanufacturers build their own pricing strategy based on predicting the pricing strategy of OEMs. In the other words, remanufacturers build their own 1-order ARA model. Moreover, we use Monte Carlo simulation to numerically analyze and compare the 1order ARA models with the classical Stackelberg models.

Findings: We research the OEM's 1-order ARA model with the uncertainty rate of recovery. That is, as OEMs, they don't know the recovery cost of remanufacturers and only know their own unit product cost c. So, they suppose the recovery cost is $\tau c(0<\tau<1)$ and $\tau$ satisfied on an uniform distribution on $[0,1]$. Based on this assumption, OEMs forecast the pricing strategy of remanufacturers. Furthermore, their own the pricing strategy which is called OEM's 1order ARA model. Similarly, as remanufacturers, they don't know the unit cost c and only know the recover $\operatorname{cost} \tau c$. Hence, they suppose $C$ is random variable and satisfied on an uniform distribution on $[0,1]$. With this assumption, remanufacturers forecast the pricing strategies of OEMs. Moreover, remanufacturers create their own the pricing strategies based on the forecasted OEMs' pricing strategies. Besides, by Monte Carlo simulation, we can come to the conclusion that pricing strategies based on 1-order ARA model have advantage over than the classical model regardless of OEMs and remanufacturers.

Research limitations/implications: We discuss OEMs and remanufacturers' 1-order ARA models are more practical than classical Stackelberg pricing strategies. In particular, on the one hand, the rate of recovery changes because of development of remanufacturing industry, improvement of new machines, disassemble-ability or other un-predicted reasons. As for OEMs, it is impossible to accurately know the rate of recovery. So, OEMs don't know the exactly pricing strategies of remanufacturers. Hence, the OEM's 1-oreder ARA model is more practical than the classical Stackelberg model and has advantage over the classical pricing strategies in profit. On the other hand, the unit production cost is not fixed but rather changed. Production technology and process improvement causes this cost to change. Similar to OEM, as for remanufacturers, they have no way to know exactly the unit production cost. Consequently, remanufacturers have more disadvantages if they use the classical pricing strategy than they use remanufacturers' 1-order ARA model. In our simulating analysis, we can come to the coincident conclusions. In general, the research on application of ARA implies that we can get more actual results with this kind of modern risk analysis method and ARA can be extensively in pricing strategies of supply chain. Moreover, the thought and method of building ARA model can be widely applied to other strategies in all kinds of economic field, such as investing strategy, the problems about auction, bidding strategies, and so on. 
Originality/value: Our research makes the pricing strategies of OEMs and remanufacturers be more actual than classical Stackelberg model and help OEMs and remanufacturers to get more profit. Furthermore, we improve the application of ARA in remanufacturing industry. Meanwhile, inspired by this analysis, we can also create different ARA models for different parameters. Furthermore, some results and analysis methods can be applied to other pricing strategies of supply chain and other economic field.

Keywords: pricing strategy, remanufacture, original equipment manufacturer, adversarial risk analysis

\section{Introduction}

\subsection{Research Background}

With the deterioration of the environment, more governments have taken various measures to improve the remanufacturing industry development and more people strengthen their protecting environment sense and are willing to buy remanufactured products. So, the remanufacturing industry has developed recently. Moreover, the remanufacturing industry has own advantages over other classical industry and has more market share than before.

All kinds of the problems related to remanufactured products have attracted attention. For example, Savaskan discusses the problem about choosing the appropriate reverse channel structure for the collection of used products from customers (Savaskan, 2011). Jaber and El Saadany create the production, remanufacture and waste disposal model with lost sales (Jaber \& El Saadany, 2009). Agrawal, Atasu and Ittersum experimentally investigate the effect of remanufactured products on the perceived value of new products (Agrawal, Atasu \& Ittersum, 2010). King, Burgess, Ijomah and McMahon discuss the importance of remanufactured products for reducing waste and protecting environment (King, Burgess, Ijomah \& McMahon, 2006). Some researchers focus on the policy influences. Webster and Mitra examine the impact of take-back laws within a manufacturer/remanufacturer competitive framework and develop a general two-period model to investigate questions of interest to policy-makers in government and managers in industry (Webster \& Mitra, 2007). Based on the general researches, many investigators begin to explore dynamic models, especially two-period models. Hiities and Yüksela address the design of automobile engines for remanufacture with quality function deploymet (Yüksela, 2010). Swaminathan characterizes the production quant self-selection and explores the effect of various parameters in the Nash equilibrium on the duopoly environment (Ferrer \& Swaminathan, 2006, 2010). Meanwhile, other researchers are more interested in the pricing strategies for dynamic models. Wu pays attention to the effects of disassemble-ability and interchangeability on the price competition ( $\mathrm{Wu}, 2013,2012 \mathrm{~b}$ ). Besides, he considers price and service between new and remanufactured products ( $\mathrm{Wu}, 2012 \mathrm{a}$ ). Mitra focuses attention on revenue management for remanufactured products and develops a pricing model to maximize the expected revenue from the recovered products (Mitra, 2007). 
In order to study pricing strategies, we will carve up markets and manufacturers. As for the market, we divide it into the primary and green segments. We believe that the primary consists of primary consumers as well as the green market is composed of green consumers (Atasu \& Wassenhove, 2008; Atasu Guide \& Wassenhove, 2008). Primary consumers deem that the new products have higher value than the remanufactured products. Nevertheless, the remanufactured products are treated with the same value as new ones by green consumers. So, green consumers prefer remanufactured products to new ones. Because there are not remanufactured products in the first period, the primary and green consumers are not different. However, in the second period, the green consumers are more willing to buy the green products than new ones, which are benefit for environment.

Suppose that there are two kinds of manufactures, which are original equipment manufacturers (OEMs) and remanufacturers. There are game relations between them $(\mathrm{Wu}$, 2013, 2012a, 2012b; Ferrer \& Swaminathan, 2006, 2010; Majumder \& Groenevelt (2001). The pricing strategies will directly affect each other's the market share and profits. Meanwhile, OEMs design for disassembly influences on the costs of OEMs and remanufacturers. To be specific, the high disassemble-ability makes it easy to repair, cleaning, inspection for OEMs. Moreover, the high disassemble-ability reduces the recover cost of remanufacturers. However, the design for high disassemble-ability increases the fixed cost of OEMs. So, in order to save fixed cost and raise the remanufacturers' cost, OEMs always will choose to the design for low disassembly. This measure makes remanufacturers erode the competitiveness as well as OEMs strengthen competitiveness.

Many elements affect on pricing strategies, such as, the proportion of green consumers in the whole market, the rate of used products being available to be remanufactured, the change of the market sizes, and so on. In this article, we consider parameters are fixed values except that the design for disassembly is two levels.

Besides, we apply a novel method to pricing strategy model, adversarial risk analysis (ARA). In the next section, we will generally introduce adversarial risk analysis. Adversarial risk analysis suggests a new perspective to study risk analysis, which combines statistical methodology and game theory (Rios-Insua, Rios \& Banks, 2009). ARA more closely press to actual conditions and more accurately forecast information than traditional risk analysis. Thus, Adversarial risk analysis is extensively applied in many area, such as economics, finance, management, engineering, environment, military, etc. (McAfee \& McMillan, 1996a, 1996b; Rothkopf, 2007; Velu \& Iyer, 2008; Heyes, 2000; Winterfeldt \& O'Sullivan, 2006).

Since adversarial risk analysis is only just beginning, most people only carefully treat on simultaneous play. There is little research dynamic game, except sketching the formulation of the Defend-attack model (Brown, Carely, Salmeron \& Wood, 2006). There are many the sequential-move games in the practical life however, for instance, chess, the guaranteed annual wage contract between labor and management (Leontief, 1946), enterprise merge and 
acquisition, used car market game (Akerlof, 1970, 2002; Akerlof \& Dickens, 1982; Bond, 1982), job market signaling (Spence, 1973). Studying the dynamic play is not adequate, so the practice applications of adversarial risk analysis are limited.

In this paper, we research the mixed play game. Particularly, it is 2-period dynamic game. In the second period, there is a simultaneous play.

\subsection{Introduction of Related Parameters}

Before we explore the model, we introduce the related parameters. The rate of used product being available to be remanufactured is noted as $\alpha$. Suppose the market has two periods. The first period consists of $s_{1}$ consumers. And, green and primary consumers are indifferent, since there is no remanufactured product. Therefore, in this period, the market is the primary market. The market scale in the second period is $s_{2}$ consumers. In this period, the market is divided into primary and green segments. Primary segment consists of primary consumers who are willing to pay for green products $\beta$ times as high as primary ones $(0<\beta<1)$. That is, if we let $\mathrm{p}_{\mathrm{n}}$, the price of new products be accepted by primary consumers in the second period, then the primary consumers prefer to pay $\beta p_{n}$ or less money for green products. Otherwise, the primary consumers won't buy the green products. While, the green consumers think green products as the same as primary ones and prefer green products. Assume that the percentage of green consumers in the whole market is $\lambda$ and the primary consumers' proportion is $1-\lambda$. The quantity of remanufactured product is restricted by the quantity of new product in the first period.

We suppose the utility of consumers in the first period is $U_{1}=\varnothing-p_{1}$, where $\varnothing$ uniform $[0,1]$ (Atasu \& Wassenhove, 2008) and $p_{1}$ is the price of new product in the first period. The utility of primary and green consumers are respectively $U_{n}=\varnothing-p_{n}$ and $U_{r}=\beta \varnothing-p_{r}$, where $p_{r}$ is the price of green products in the second period. $\mathrm{q}_{\mathrm{r}}, \mathrm{q}_{\mathrm{n}}$ and $\mathrm{q}_{1}$ respectively are the demand quantity of remanufactuered products, new products in the second period and the demand quantity of new products in the first period. Further suppose that $\mu$ is the proportion in the collected end-life-cycle products which are used by remanufacturers.

Remanufacturers' pricing strategies are high $\mathrm{G}$ and low S. The rate of discount is $\delta$.

Now, it is needed to think that the remanufacturing problem under restricted condition is as follows:

$$
\operatorname{maxE}\left[\Pi_{\mathrm{r}}^{\mathrm{j}}\right]=\operatorname{maxE}\left[\delta\left(\mathrm{p}_{\mathrm{r}}-\tau c\right) \mathrm{q}_{\mathrm{r}}^{\mathrm{j}}\right], \quad \text { s.t. } \mathrm{q}_{\mathrm{r}}^{\mathrm{j}}<u \mathrm{q}_{1,}
$$

where $j \in\{S, G\}$.

This paper is organized as follows. In section 2, we study OEMs' 1-order ARA model. Particularly, as an OEM, they don't the rate of recovery of remanufacturers, so they have to estimate remanufacturer's pricing strategy. Moreover, based on the forecasted results, OEMs 
build their own pricing strategy, which is called OEM's 1-order ARA pricing strategy model. In the next section, we discuss remanufacturers' 1-order ARA model. Especially, considering from remanufacturers' point, since remanufacturers don't know the unit production cost, we have to predict OEMs' pricing strategies. Then, we research remanufacturers' own pricing strategies based on the forecasted OEMs' pricing strategies. In section 4, we numerically simulate by Monte Carlo method. Through generating a series of random parameters, we simulate reality and find that our 1-order ARA models have advantage over classical pricing strategies for both OEMs and remanufacturers. At last, we talk about the conclusion and the further research.

\section{OEMs Build Their Own Pricing Strategy - OEM's 1-order ARA Pricing Strategy Model}

In reality, the rate of recovery changes because of development of remanufacturing industry, improvement of new machines, disassemble-ability or other un-predicted reasons. As for OEMs, it is impossible to accurately know the rate of recovery. So, OEMs don't know the exactly pricing strategies of remanufacturers.

In this section, considering from OEMs' point, we only know the OEMs' unit production cost c and don't know the remanufacturers' recovery cost $\tau c(0<\tau<1)$. So, OEMs don't know the pricing strategy of remanufacturers and have to predict remanufacturers' pricing strategy. Based on this predicted pricing strategy, we build OEM's own pricing strategy. That is, it is called as 1-order ARA model of OEMs.

We firstly consider two cases, which are remanufacturers accept low-pricing strategy and high-pricing strategy. Especially, if remanufacturers accept low-pricing strategy, OEMs predict the concrete pricing strategy of remanufacturers. Similarly, if remanufacturers accept highpricing strategy, OEMs estimate concrete pricing strategy of remanufacturers. Then, OEMs create their own pricing strategy based on these predicted pricing strategy of remanufacturers.

\subsection{OEM Estimate Remanufacturer's Pricing Strategy Model}

Suppose that OEM's unit production cost is C. OEM estimate that remanufacturer's recovery cost is $\tau c(0<\tau<1)$ and $\tau$ satisfied on a uniform distribution on $[0,1]$. Correspondingly, the fixed cost of OEM is $v c(0<v<M)$. 


\subsubsection{OEMs Estimate the Pricing Strategy of Remanufacturers under the Remanufacturer's Low-Pricing Strategy}

We firstly think about the case $\mathrm{p}_{\mathrm{r}}<\beta \mathrm{p}_{\mathrm{n}}$. At this time, OEM believe remanufacturer's the lowpricing strategy is as follows:

Proposition 2.1. (i) when

$$
p_{n} \geq \frac{2 \beta \lambda+\tau(\eta+\lambda \beta)}{2 \beta(\eta+2 \lambda \beta)}
$$

remanufacturers choose the low-pricing strategies.

(ii) If

$$
S_{2}<\frac{4 \mu \beta\left(1-P_{1}\right) S_{1}}{2 \beta\left(\eta p_{n}+\lambda\right)-c(\eta+\lambda \beta)}
$$

i.e. the remanufacturing is unbound by collection, then remanufacturer's optimal pricing strategy is

$$
\mathrm{p}_{\mathrm{r}, \mathrm{s}}^{*}=\frac{2 \beta\left(\eta \mathrm{p}_{\mathrm{n}}+\lambda\right)+\mathrm{c}(\eta+\lambda \beta)}{4(\eta+\beta \lambda)}
$$

Otherwise, i.e. the remanufacturing is bound by collection,

$$
p_{r, s}^{*}=\frac{s_{2} \beta\left(\eta p_{n}+\lambda\right)-\mu \beta\left(1-p_{1}\right) S_{1}}{s_{2}(\eta+\beta \lambda)}
$$

Proof: When $\mathrm{q}_{\mathrm{r}}^{\mathrm{S}} \leq \mu \mathrm{q}_{1}$, it is easy to see that

$$
\mathrm{q}_{\mathrm{r}}^{\mathrm{S}}=(1-\lambda) \mathrm{S}_{2} \frac{\beta \mathrm{p}_{\mathrm{n}}-\mathrm{p}_{\mathrm{r}}}{\beta(1-\beta)}+\lambda S_{2}\left(1-\mathrm{p}_{\mathrm{r}}\right) .
$$

As for OEM, he thinks that remanufacturer's the object function is

$$
\Pi_{r}^{j}=\delta\left(p_{r}-\tau c\right)\left((1-\lambda) S_{2} \frac{\beta p_{n}-p_{r}}{\beta(1-\beta)}+\lambda S_{2}\left(1-p_{r}\right)\right) .
$$

So,

$$
\begin{aligned}
E\left[\Pi_{r}^{j}\right] & =E\left[\delta\left(p_{r}-\tau c\right) q_{r}^{j}\right] \\
& =\int_{0}^{1} \delta\left(p_{r}-\tau c\right)\left((1-\lambda) S_{2} \frac{\beta p_{n}-p_{r}}{\beta(1-\beta)}+\lambda S_{2}\left(1-p_{r}\right)\right) d \tau \\
& =\delta\left(p_{r}-\frac{c}{2}\right)\left(\eta S_{2} p_{n}-\frac{\eta}{\beta} S_{2} p_{r}+\lambda S_{2}-\lambda S_{2} p_{r}\right) .
\end{aligned}
$$

We come back to the Equation (1). We only need to let

$$
\frac{\partial \mathrm{E}\left[\Pi_{\mathrm{r}}^{\mathrm{j}}\right]}{\partial \mathrm{p}_{\mathrm{r}}}=0,
$$

in order to get the maximal value of $\mathrm{E}\left[\Pi_{\mathrm{r}}^{\mathrm{i}, \mathrm{j}}\right]$.

Detailedly, 


$$
\begin{aligned}
\frac{\partial}{\partial p_{r}} & E\left[\Pi_{r}^{i, j}\right] \\
& =\delta\left(\eta S_{2} p_{n}+\lambda S_{2}\right)-2 \delta p_{r}\left(\frac{\eta}{\beta} S_{2}+\lambda S_{2}\right)+\frac{\delta c}{2}\left(\frac{\eta}{\beta} S_{2}+\lambda S_{2}\right) \\
& =0 .
\end{aligned}
$$

That is,

$$
\mathrm{p}_{\mathrm{r}, \mathrm{s}}^{*}=\frac{2 \beta\left(\eta \mathrm{p}_{\mathrm{n}}+\lambda\right)+\mathrm{c}(\eta+\lambda \beta)}{4(\eta+\beta \lambda)}
$$

It is Ecuation (4).

Noticing

$$
\mathrm{q}_{\mathrm{r}}^{\mathrm{S}} \leq \mu \mathrm{q}_{1}
$$

we have

$$
\mathrm{S}_{2} \leq \frac{\mu \beta \mathrm{S}_{1}\left(1-\mathrm{p}_{1}\right)}{\beta\left(\mathrm{p}_{\mathrm{n}} \eta+\lambda\right)-\mathrm{p}_{\mathrm{r}}(\eta+\lambda \beta)}
$$

Where $\eta=(1-\lambda) /(1-\beta)$.

Applying Equation (4) to (6), we can get Equation (3).

We apply Equation (4) to $\mathrm{p}_{\mathrm{r}} \leq \beta \mathrm{p}_{\mathrm{n}}$ we can obtain Equation (2).

When $\mathrm{q}_{\mathrm{r}}^{\mathrm{S}} \geq \mu \mathrm{q}_{1}$, from $\mathrm{q}_{\mathrm{r}}^{\mathrm{S}}=\mu \mathrm{q}_{1}$, we can get Equation (5).

\subsubsection{OEMs Estimate the Pricing Strategy of Remanufacturers under the Remanufacturer's High-Pricing Strategy}

Now, we pay attention to the case $\mathrm{p}_{\mathrm{r}}>\mathrm{pp}_{\mathrm{n}}$ In other words, we should use the high pricing strategy.

Proposition 2.2. When remanufacturers accept the high pricing strategy, the best choice of remanufacturers is

$$
\mathrm{p}_{\mathrm{r}, \mathrm{G}}^{*}=\frac{1}{2}+\frac{1}{4} \mathrm{c},
$$

if

$$
\mathrm{S}_{2} \leq \frac{4 \mu \mathrm{S}_{1}\left(1-\mathrm{p}_{1}\right)}{\lambda(2-\mathrm{c})},
$$

i.e. the remanufacturing is unbound by collection.

Otherwise, i.e. the remanufacturing is bound by collection,

$$
\mathrm{p}_{\mathrm{r}, \mathrm{G}}^{*}=\frac{\lambda \mathrm{S}_{2}-\mu \mathrm{S}_{1}\left(1-\mathrm{p}_{1}\right)}{\lambda \mathrm{S}_{2}} .
$$

Proof: When remanufacturers accept the high pricing strategy, it is not difficult to state that

$$
\mathrm{q}_{\mathrm{r}}^{\mathrm{G}}=\lambda \mathrm{S}_{2}\left(1-\mathrm{p}_{\mathrm{r}}\right)
$$


and

$$
\Pi_{\mathrm{r}}^{\mathrm{j}}=\delta\left(\mathrm{p}_{\mathrm{r}}-\tau \mathrm{c}\right) \lambda S_{2}\left(1-\mathrm{p}_{\mathrm{r}}\right)
$$

OEM estimate that

$$
\begin{aligned}
& E\left[\Pi_{r}^{i, j}\right]=\int_{0}^{1} \delta\left(p_{r}-\tau c\right) \lambda S_{2}\left(1-p_{r}\right) d \tau \\
& =\delta p_{r} \lambda S_{2}\left(1-p_{r}\right)-\frac{1}{2} \delta c \lambda S_{2}\left(1-p_{r}\right)
\end{aligned}
$$

It is easy to see that we only need to let

$$
\frac{\partial \mathrm{E}\left[\Pi_{\mathrm{r}}^{\mathrm{i}, \mathrm{j}}\right]}{\partial \mathrm{p}_{\mathrm{r}}}=0
$$

to achieve the optimal solution of $E\left[\Pi_{\mathrm{r}}^{\mathrm{i}, j}\right]$. That is,

$$
\mathrm{p}_{\mathrm{r}, \mathrm{G}}^{*}=\frac{1}{2}+\frac{1}{4} \mathrm{c} \text {. }
$$

It is Equation (7). Noting $\mathrm{q}_{\mathrm{r}}^{\mathrm{G}} \leq \mu \mathrm{q}_{1}$ we have

$$
S_{2} \leq \frac{\mu S_{1}\left(1-p_{1}\right)}{\lambda\left(1-p_{r}\right)}
$$

Applying Equation (7) to (10), we get (8).

When $\mathrm{q}_{\mathrm{r}}^{\mathrm{G}} \geq \mu \mathrm{q}_{1}$ we can get Equation (9) with $\mathrm{q}_{\mathrm{r}}^{\mathrm{S}}=\mu \mathrm{q}_{1}$.

\subsection{OEM Build Their Own Pricing Strategy Based on Predicted Remanufacturer's Pricing Strategies - OEM's 1-order ARA Pricing Strategy Models}

\subsubsection{OEM's 1-order ARA Pricing Strategy Model when Remanufacturers Choose the High-Pricing Strategy}

We first discuss the case of remanufacturer's high pricing strategy.

Theorem 2.3. Suppose remanufacturers choose the high pricing strategy.

OEM's pricing strategies is $\mathrm{p}_{1, \mathrm{G}}^{*}=\mathrm{p}_{\mathrm{n}, \mathrm{G}}^{*}=\frac{1+\mathrm{c}}{2}$.

Proof: When the remanufacturer use the high-pricing strategy, the market demand of new products in the second period is

$$
\mathrm{q}_{n}^{\mathrm{G}}=(1-\lambda) \mathrm{S}_{2}\left(1-\mathrm{p}_{\mathrm{n}}\right)
$$

Therefore, the utility function of OEM

$$
\Pi_{\mathrm{n}}^{\mathrm{i}}=\left(\left(\mathrm{p}_{1}-\mathrm{c}\right) \mathrm{S}_{1}\left(1-\mathrm{p}_{1}\right)-v \mathrm{c}\right)+\delta\left(\mathrm{p}_{\mathrm{n}}-\mathrm{c}\right)(1-\lambda) \mathrm{S}_{2}\left(1-\mathrm{p}_{\mathrm{n}}\right)
$$

Let $\frac{\partial}{\partial \mathrm{p}_{1}} \Pi_{\mathrm{n}}^{\mathrm{iS}}=0$ and $\frac{\partial}{\partial \mathrm{p}_{\mathrm{n}}} \Pi_{\mathrm{n}}^{\mathrm{iS}}=0$.

Then, $\mathrm{p}_{1}^{*}=\mathrm{p}_{\mathrm{n}}^{*}=\frac{1+\mathrm{c}}{2}$. 


\subsubsection{OEM's1-order ARA Pricing Strategy Model when Remanufacturers Choose the Low-Pricing Strategy}

Theorem 2.4. (i) When remanufacturers choose the low pricing strategy and remanufacturing is unbound by collection, OEMs' pricing strategy is

$$
\begin{gathered}
\mathrm{p}_{1, \mathrm{~S}, \mathrm{G}}^{*}=\frac{1+\mathrm{c}}{2}, \\
\mathrm{p}_{\mathrm{n}, \mathrm{S}, \mathrm{U}}^{*}=\frac{4(1-\beta)(\eta+\beta \lambda)+\mathrm{c}(\eta+\beta \lambda)+2 \mathrm{c \eta}(2+\beta)+2 \beta \lambda(2 \mathrm{c}-1)}{8(\eta+\beta \lambda)+4 \beta \eta}, \\
\mathrm{p}_{\mathrm{r}, \mathrm{S}}^{*}=\frac{2 \beta\left(\eta \mathrm{p}_{\mathrm{n}, \mathrm{S}}^{*}+\lambda\right)+\mathrm{c}(\eta+\lambda \beta)}{4(\eta+\beta \lambda)} ;
\end{gathered}
$$

(ii) When remanufacturers choose the low pricing strategy and remanufacturing is bound by collection, OEMs' pricing strategy is

$$
\begin{gathered}
\mathrm{p}_{1, \mathrm{~S}, \mathrm{~B}}^{*}=\left(2 \lambda^{2} \mathrm{~S}_{2} \beta^{2}+\beta\left(-\mu \mathrm{S}_{1} \beta+\lambda \mathrm{S}_{2}(4+(-2+\mu) \beta)\right) \eta+\Psi_{2} \mathrm{~S}_{1}\right. \\
+\mu \mathrm{S}_{2} \beta \eta(\lambda \beta+\eta)(1-\beta)+\frac{\mathrm{S}_{2}(\lambda \beta+\eta-\beta \eta)(2 \lambda \beta+2 \eta-\mu \beta \eta) \mathrm{c}}{\Psi_{1}}, \\
\mathrm{p}_{\mathrm{n}, \mathrm{S}, \mathrm{B}}^{*}=\left(-\beta\left(\mu \mathrm{S}_{1}-2 \beta \mathrm{S}_{2}\right)(\lambda \beta+\eta)+2 \mathrm{~S}_{2}(\lambda \beta+\eta)^{2}(1-\beta)\left(\beta^{2} \lambda\left(\mu \mathrm{S}_{1}+2 \lambda \mathrm{S}_{2}\right)\right.\right. \\
\left.+\lambda\left(\mu \mathrm{S}_{1}+4 \lambda \mathrm{S}_{2}-\left(\mu^{2} \mathrm{~S}_{1}+2 \lambda \mathrm{S}_{2}\right) \beta\right) \eta+\mathrm{S}_{1} \Psi_{2}\right) \frac{\mathrm{c}}{\Psi_{1}}
\end{gathered}
$$

where

$$
\begin{gathered}
\Psi_{1}=4 \lambda^{2} S_{2} \beta^{2}-\beta\left(4 \lambda S_{2}(-2+\beta)+\mu^{2} \beta\right) \eta-4 S_{2}(-1+\beta) \eta^{2} \\
\Psi_{2}=2 S_{2}(1-\beta) \eta^{2} .
\end{gathered}
$$

Proof: At first, we consider that what response the OEM should be when the remanufacturer use the low-pricing strategy. The market demand of new products in the second period is

$$
\mathrm{q}_{\mathrm{n}}^{\mathrm{S}}=(1-\lambda) \mathrm{S}_{2}\left(\frac{1-\beta-\mathrm{p}_{\mathrm{n}}+\mathrm{p}_{\mathrm{r}}}{1-\beta}\right)
$$

Therefore,

$$
\mathrm{E}\left[\Pi_{\mathrm{n}}^{\mathrm{S}}\right]=\mathrm{S}_{1}\left(1-\mathrm{p}_{1}\right)\left(\mathrm{p}_{1}-\mathrm{c}\right)-\frac{v}{2}+\delta \mathrm{S}_{2} \eta\left(\mathrm{p}_{\mathrm{n}}-\mathrm{c}\right)\left(1-\beta-\mathrm{p}_{\mathrm{n}}-\mathrm{p}_{\mathrm{r}}\right)
$$

Let $\frac{\partial}{\partial \mathrm{p}_{1}} \mathrm{E}\left[\Pi_{\mathrm{n}}^{\mathrm{iS}}\right]=0$.

We can get $p_{1, S}^{*}=\frac{1+c}{2}$.

Set $\frac{\partial}{\partial \mathrm{p}_{\mathrm{n}}} \mathrm{E}\left[\Pi_{\mathrm{n}}^{\mathrm{iS}}\right]=0$.

We can obtain

$$
1-\beta-2 p_{n}-p_{r}-p_{n} p_{r}^{\prime}+c+c p_{r}^{\prime}=0 .
$$

So, $4(1-\beta)(\eta+\beta \lambda)-8(\eta+\beta \lambda) p_{n}-2 \beta\left(\eta p_{n}+\lambda\right)$

$+c(\eta+\beta \lambda)-2 p_{n} \beta \eta+4 c(\eta+\beta \lambda)+2 c \beta \eta=0$. 
Hence,

$$
p_{n, S}^{*}=\frac{4(1-\beta)(\eta+\beta \lambda)+c(\eta+\beta \lambda)+2 c \eta(2+\beta)+2 \beta \lambda(2 c-1)}{8(\eta+\beta \lambda)+4 \beta \eta},
$$

When remanufacturing is unbound by collection, noting Theorem 2.1 , we can

$$
\mathrm{p}_{\mathrm{r}, \mathrm{S}}^{*}=\frac{2 \beta\left(\eta \mathrm{p}_{\mathrm{n}, \mathrm{S}}^{*}+\lambda\right)+\mathrm{c}(\eta+\lambda \beta)}{4(\eta+\beta \lambda)}
$$

When remanufacturing is bound by collection, we prove similarly except for $q_{r}^{S}=\mu q_{1}$.

\section{Remanufacturers Build Their Own Pricing Strategy - Remanufacturer's 1-order} ARA Pricing Strategy Model

In fact, the unit production cost is not fixed but rather changed. Production technology and process improvement causes the cost to change. Similar to OEM, as for remanufacturers, they have no way to know exactly the unit production cost.

In this section, considering from remanufacturers' point, we don't know the OEMs' unit production cost $c$ and only know the remanufacturers' recovery $\operatorname{cost} \tau c(0<\tau<1)$. So, remanufacturers don't know the pricing strategy of OEMs and have to predict OEMs' pricing strategy. Based on this predicted pricing strategy of OEMs, we build remanufacturers' own pricing strategy. That is, it is called as 1-order ARA model of remanufacturers.

Similar to the above, firstly, we also consider two cases, which are remanufacturers accept low-pricing strategy and high-pricing strategy. Especially, if remanufacturers accept low-pricing strategy, remanufacturers predict the concrete pricing strategy of OEMs. Similarly, if remanufacturers accept high-pricing strategy, remanufacturers estimate concrete pricing strategy of OEMs. Then, remanufacturers create their own pricing strategy based on these predicted pricing strategy of OEMs.

\subsection{Remanufacturers Estimate the Pricing Strategy of OEMs}

\subsubsection{Remanufacturers Estimate the Pricing Strategy of OEMs under the Remanufacturer's Low-Pricing Strategy}

Proposition 3.1. (i) When remanufacturers choose the low pricing strategy and remanufacturing is unbound by collection, OEM's pricing strategies are 


$$
\begin{aligned}
& \mathrm{p}_{1, \mathrm{~S}, \mathrm{G}}^{*}=\frac{1+\mathrm{c}}{2}, \\
& \mathrm{p}_{\mathrm{n}, \mathrm{S}, \mathrm{U}}^{*}=\frac{4(1-\beta)(\eta+\beta \lambda)+\mathrm{c}(\eta+\beta \lambda)+2 \mathrm{c \eta}(2+\beta)+2 \beta \lambda(2 \mathrm{c}-1)}{8(\eta+\beta \lambda)+4 \beta \eta}, \\
& \mathrm{p}_{\mathrm{r}, \mathrm{S}}^{*}=\frac{2 \beta\left(\eta \mathrm{p}_{\mathrm{n}, \mathrm{S}}^{*}+\lambda\right)+\mathrm{c}(\eta+\lambda \beta)}{4(\eta+\beta \lambda)} ;
\end{aligned}
$$

(ii) When remanufacturers choose the low pricing strategy and remanufacturing is bound by collection, OEM's pricing strategies are

$$
\begin{gathered}
\mathrm{p}_{1, \mathrm{~S}, \mathrm{~B}}^{*}=\left(2 \lambda^{2} \mathrm{~S}_{2} \beta^{2}+\beta\left(-\mu \mathrm{S}_{1} \beta+\lambda \mathrm{S}_{2}(4+(-2+\mu) \beta)\right) \eta+\Psi_{2} \mathrm{~S}_{1}\right. \\
+\mu \mathrm{S}_{2} \beta \eta(\lambda \beta+\eta)(1-\beta)+\frac{\mathrm{S}_{2}(\lambda \beta+\eta-\beta \eta)(2 \lambda \beta+2 \eta-\mu \beta \eta) c}{\Psi_{1}} \\
\mathrm{p}_{\mathrm{n}, \mathrm{S}, \mathrm{B}}^{*}=\left(-\beta\left(\mu \mathrm{S}_{1}-2 \beta \mathrm{S}_{2}\right)(\lambda \beta+\eta)+2 \mathrm{~S}_{2}(\lambda \beta+\eta)^{2}(1-\beta)\left(\beta^{2} \lambda\left(\mu \mathrm{S}_{1}+2 \lambda S_{2}\right)\right.\right. \\
\left.+\lambda\left(\mu \mathrm{S}_{1}+4 \lambda S_{2}-\left(\mu^{2} S_{1}+2 \lambda S_{2}\right) \beta\right) \eta+S_{1} \Psi_{2}\right) \frac{\mathrm{c}}{\Psi_{1}}
\end{gathered}
$$

where

$$
\begin{gathered}
\Psi_{1}=4 \lambda^{2} S_{2} \beta^{2}-\beta\left(4 \lambda S_{2}(-2+\beta)+\mu^{2} \beta\right) \eta-4 S_{2}(-1+\beta) \eta^{2}, \\
\Psi_{2}=2 S_{2}(1-\beta) \eta^{2} .
\end{gathered}
$$

Proof: At first, we consider that what response the OEM should be when the remanufacturer use the low-pricing strategy. The market demand of new products in the second period is

$$
\mathrm{q}_{\mathrm{n}}^{\mathrm{S}}=(1-\lambda) \mathrm{S}_{2}\left(\frac{1-\beta-\mathrm{p}_{\mathrm{n}}+\mathrm{p}_{\mathrm{r}}}{1-\beta}\right)
$$

Therefore,

$$
E\left[\Pi_{n}^{S}\right]=S_{1}\left(1-p_{1}\right)\left(p_{1}-c\right)-\frac{v}{2}+\delta S_{2} \eta\left(p_{n}-c\right)\left(1-\beta-p_{n}-p_{r}\right) .
$$

Let $\frac{\partial}{\partial \mathrm{p}_{1}} \mathrm{E}\left[\Pi_{\mathrm{n}}^{\mathrm{iS}}\right]=0$

We can get

$\mathrm{p}_{1, \mathrm{~S}}^{*}=\frac{1+\mathrm{c}}{2}$.

Set $\frac{\partial}{\partial \mathrm{p}_{\mathrm{n}}} \mathrm{E}\left[\Pi_{\mathrm{n}}^{\mathrm{iS}}\right]=0$.

We can obtain

$1-\beta-2 p_{n}-p_{r}-p_{n} p_{r}^{\prime}+c+c p_{r}^{\prime}=0$.

So, $4(1-\beta)(\eta+\beta \lambda)-8(\eta+\beta \lambda) p_{n}-2 \beta\left(\eta p_{n}+\lambda\right)$

$+c(\eta+\beta \lambda)-2 p_{n} \beta \eta+4 c(\eta+\beta \lambda)+2 c \beta \eta=0$.

Hence,

$$
p_{n, S,}^{*}=\frac{4(1-\beta)(\eta+\beta \lambda)+c(\eta+\beta \lambda)+2 c \eta(2+\beta)+2 \beta \lambda(2 c-1)}{8(\eta+\beta \lambda)+4 \beta \eta}
$$


When remanufacturing is unbound by collection, noting Theorem 2.1 , we can

$$
p_{r, S}^{*}=\frac{2 \beta\left(\eta p_{n, S}^{*}+\lambda\right)+c(\eta+\lambda \beta)}{4(\eta+\beta \lambda)}
$$

When remanufacturing is bound by collection, we prove similarly except for $q_{r}^{S}=\mu q_{1}$.

\subsubsection{Remanufacturers Estimate the Pricing Strategy of OEMs under the Remanufacturer's High-Pricing Strategy}

Proposition 3.2. If remanufacturers accept high-pricing strategy, OEM's pricing strategies is

$$
\mathrm{p}_{1, \mathrm{G}}^{*}=\mathrm{p}_{\mathrm{n}, \mathrm{G}}^{*}=\frac{1+\mathrm{c}}{2} \text {. }
$$

This proposition can be proved by method similar to Proposition 2.2.

\subsection{Remanufacturers Build Their Own Pricing Strategy Based on Predicted OEM's} Pricing Strategies - Remanufacturers' 1-order ARA Pricing Strategy Models

\subsubsection{Remanufacturers' 1-order ARA Pricing Strategy Model when Remanufacturers Accept Low-Pricing Strategy}

Now, as for remanufacturer, we build their own pricing strategies model. To begin, we research their low pricing strategy.

\section{Theorem 3.3.}

(i) When

$$
p_{n} \geq \frac{\beta \lambda+c(\eta+\lambda \beta)}{\beta(\eta+2 \beta \lambda)}
$$

remanufacturers choose the low-pricing strategies.

(ii) If

$$
S_{2}<\frac{2 \mu \beta\left(1-p_{1}\right) S_{1}}{\beta\left(\eta p_{n, S, U}^{*}+\lambda\right)-c(\eta+\lambda \beta)}
$$

i.e. the remanufacturing is unbound by collection,

the remanufacturer's optimal pricing strategy is

$$
\mathrm{p}_{\mathrm{r}, \mathrm{S}}^{*}=\frac{2\left(\eta \mathrm{p}_{\mathrm{n}, \mathrm{S}, \mathrm{U}}^{*}+\lambda\right)+\mathrm{c}(\eta+\lambda \beta)}{4(\eta+\lambda \beta)} ;
$$

Otherwise, i.e. the remanufacturing is bound by collection,

$$
\mathrm{p}_{\mathrm{r}, \mathrm{S}}^{*}=\frac{\mathrm{S}_{2} \beta\left(\eta \mathrm{p}_{\mathrm{n}, \mathrm{S}, \mathrm{B}}^{*}+\lambda\right)-\mu \beta\left(1-\mathrm{p}_{1, \mathrm{~S}, \mathrm{~B}}^{*}\right) \mathrm{S}_{1}}{\mathrm{~S}_{2}(\eta+\lambda \beta)} .
$$


Proof: When $\mathrm{q}_{\mathrm{r}}^{\mathrm{S}} \leq \mu \mathrm{q}_{1}$, it is easy to show that

$$
\mathrm{q}_{\mathrm{r}}^{\mathrm{S}}=(1-\lambda) \mathrm{S}_{2} \frac{\beta \mathrm{p}_{\mathrm{n}}-\mathrm{p}_{\mathrm{r}}}{\beta(1-\beta)}+\lambda \mathrm{S}_{2}\left(1-\mathrm{p}_{\mathrm{r}}\right)
$$

And OEM thinks that remanufacturer's the object function is

$$
\Pi_{r}^{j}=\delta\left(p_{r}-\tau c\right)\left((1-\lambda) S_{2} \frac{\beta p_{n}-p_{r}}{\beta(1-\beta)}+\lambda S_{2}\left(1-p_{r}\right)\right)
$$

We come back to the Equation (1). We only need to let

$$
\frac{\partial \Pi_{\mathrm{r}}^{\mathrm{j}}}{\partial \mathrm{p}_{\mathrm{r}}}=0
$$

in order to get the maximal value of $\mathrm{E}\left[\Pi_{\mathrm{r}}^{\mathrm{ij}}\right]$.

Detailedly,

$$
\frac{\partial}{\partial \mathrm{p}_{\mathrm{r}}} \Pi_{\mathrm{r}}^{\mathrm{i}, \mathrm{j}}=\delta\left(\eta \mathrm{S}_{2} \mathrm{p}_{\mathrm{n}}+\lambda \mathrm{S}_{2}\right)-2 \delta \mathrm{p}_{\mathrm{r}}\left(\frac{\eta}{\beta} S_{2}+\lambda S_{2}\right)+\delta \tau c\left(\frac{\eta}{\beta} S_{2}+\lambda S_{2}\right)=0
$$

That is,

$$
p_{r, s}^{*}=\frac{\beta\left(\eta p_{n}+\lambda\right)+c(\eta+\lambda \beta)}{2(\eta+\beta \lambda)} .
$$

Combining Theorem 3.1, we have Equation (14).

Observing

$$
\mathrm{q}_{\mathrm{r}}^{\mathrm{s}} \leq \mu \mathrm{q}_{1}
$$

we have

$$
S_{2} \leq \frac{\mu \beta S_{1}\left(1-p_{1}\right)}{\beta\left(p_{n} \eta+\lambda\right)-p_{r}(\eta+\lambda \beta)},
$$

Where

$$
\eta=\frac{1-\lambda}{1-\beta}
$$

Applying Equation (14) to (16), we can get Equation (13).

We apply Equation (14) to $\mathrm{p}_{\mathrm{r}}<\beta \mathrm{p}_{\mathrm{n}}$, we can obtain Equation (12). 
When

$$
\mathrm{q}_{\mathrm{r}}^{\mathrm{S}} \geq \mu \mathrm{q}_{1}
$$

from

$$
\mathrm{q}_{\mathrm{r}}^{\mathrm{S}}=\mu \mathrm{q}_{1}
$$

and Theorem 3.2, we can get Equation (15).

\subsubsection{Remanufacturers' 1-order ARA Pricing Strategy Model when Remanufacturers Accept High-Pricing Strategy}

Now, we pay attention to the case

$$
\mathrm{p}_{\mathrm{r}}>\rho \mathrm{p}_{\mathrm{n}} .
$$

In other words, we should use the high pricing strategy.

Theorem 3.4. When remanufacturers accept the high pricing strategy, the best choice of remanufacturers is

$$
\mathrm{p}_{\mathrm{r}, \mathrm{G}}^{*}=\frac{1+\tau \mathrm{c}}{2}
$$

if

$$
\mathrm{S}_{2} \leq \frac{2 \mu \mathrm{S}_{1}\left(1-\mathrm{p}_{1, \mathrm{G}, \mathrm{U}}^{*}\right)}{\lambda(1-\tau \mathrm{c})}
$$

i.e. the remanufacturing is unbound by collection.

Otherwise, i.e. the remanufacturing is bound by collection,

$$
\mathrm{p}_{\mathrm{r}, \mathrm{G}}^{*}=\frac{\lambda \mathrm{S}_{2}-\mu \mathrm{S}_{1}\left(1-\mathrm{p}_{1, \mathrm{G}, \mathrm{B}}^{*}\right)}{\lambda \mathrm{S}_{2}} .
$$

Proof: we can see that

$$
\mathrm{q}_{\mathrm{r}}^{\mathrm{G}}=\lambda \mathrm{S}_{2}\left(1-\mathrm{p}_{\mathrm{r}}\right)
$$

And

$$
\Pi_{\mathrm{r}}^{\mathrm{j}}=\delta\left(\mathrm{p}_{\mathrm{r}}-\tau \mathrm{c}\right) \lambda S_{2}\left(1-\mathrm{p}_{\mathrm{r}}\right) .
$$

It is easy to show that we only need to let

$$
\frac{\partial \Pi_{\mathrm{r}}^{\mathrm{i}, \mathrm{j}}}{\partial \mathrm{p}_{\mathrm{r}}}=0
$$

to achieve the optimal solution of $\mathrm{E}\left[\Pi_{\mathrm{r}}^{\mathrm{ij}}\right]$. That is,

$$
\mathrm{p}_{\mathrm{r}, \mathrm{G}}^{*}=\frac{1+\tau \mathrm{c}}{2} \text {. }
$$


It is Equation (17). Noticing

$$
\mathrm{q}_{\mathrm{r}}^{\mathrm{G}} \leq \mu \mathrm{q}_{1}
$$

we have

$$
S_{2} \leq \frac{\mu S_{1}\left(1-p_{1}\right)}{\lambda\left(1-p_{r}\right)}
$$

Applying Equation (17) to (20), we can get Equation (18).

When $\mathrm{q}_{\mathrm{r}}^{\mathrm{G}} \geq \mu \mathrm{q}_{1}$.

we can get Equation (19) from $q_{r}^{G}=\mu q_{1}$.

\section{The Numerical Simulation}

In this section, we simulate the classical pricing strategies and the pricing strategies based on 1-order ARA model and compare with them. Though comparing with simulated results, we find that the 1-order ARA pricing strategies have advantage over the classical pricing strategies.

Firstly, we investigate the OEM's pricing strategy. We generate a series of random numbers as values of $\tau$ by Monte Carlo simulation, which lead to the randomness of remanufacturers' pricing strategies. According to the above results, we can achieve OEM's pricing strategy based on 1-order ARA model (Figure 1) and the classical OEM's pricing strategy (Figure 2).

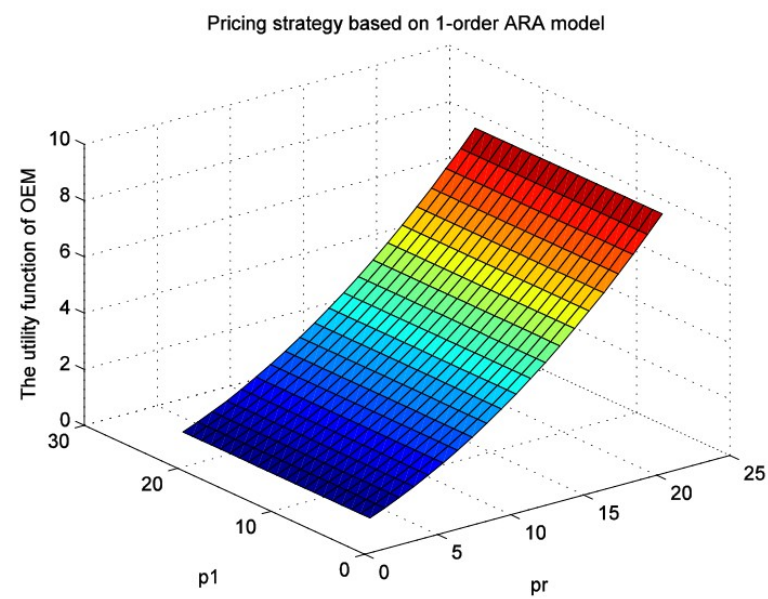

Figure 1. The OEM's pricing strategy based on 1-order ARA model

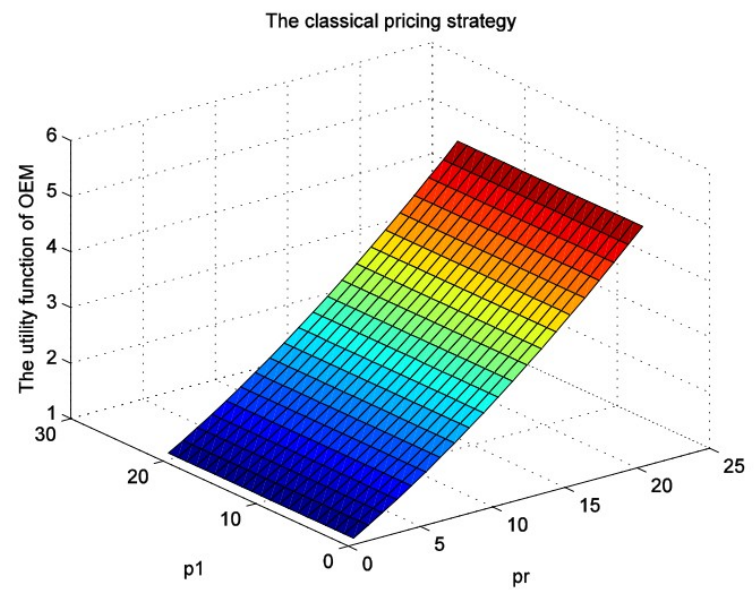

Figure 2. The classical OEM's pricing strategy

From Figure 1 and Figure 2, we can observe that the utility function value of OEM based on 1-order ARA model is bigger than the classical model, so we can tell that the OEM's pricing strategy based on 1-order ARA model is better than the classical pricing strategy. In reality, the rate of recovery changes because of development of remanufacturing industry, improvement of new machines, disassemble-ability or other un-predicted reasons. As for 
OEMs, it is impossible to accurately know the rate of recovery. So, OEMs don't know the exactly pricing strategies of remanufacturers. Hence, the OEM's 1-oreder ARA model is more practical than the classical Stackelberg model and has advantage over the classical pricing strategies in profit. In our simulating analysis, we can come to the coincident conclusion.

Next, we focus on the remanufacturers' pricing strategy based on1-order ARA model. Similarly, we generate a series of random numbers as the values of $\mathrm{c}$ by Monte Carlo simulation. Based on the random values of $\mathrm{c}$, the OEMs' pricing strategies become random. With the fixed demand quantity of new and remanufactured products, we obtain the remanufacturers' pricing strategies based on 1-order ARA model (Figure 3 ) and the classical pricing strategies (Figure 4).

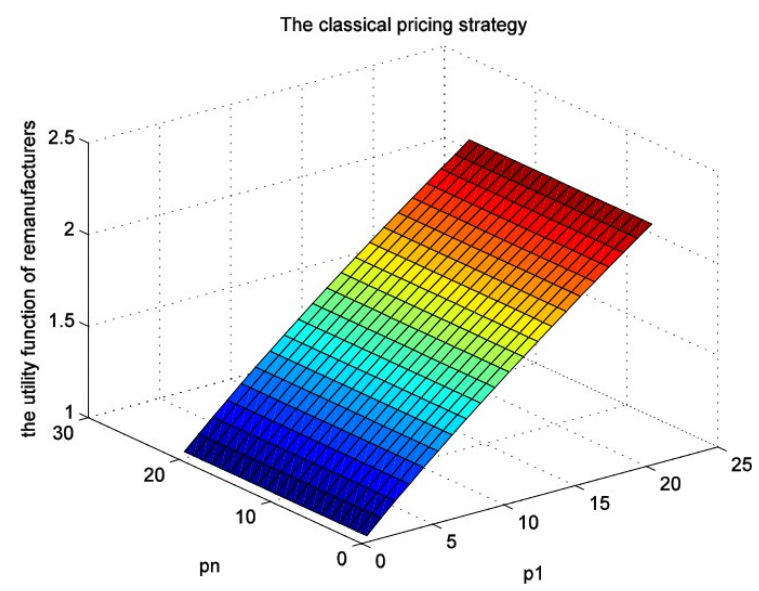

Figure 3. The remanufacturers' pricing strategy based on 1-order ARA model

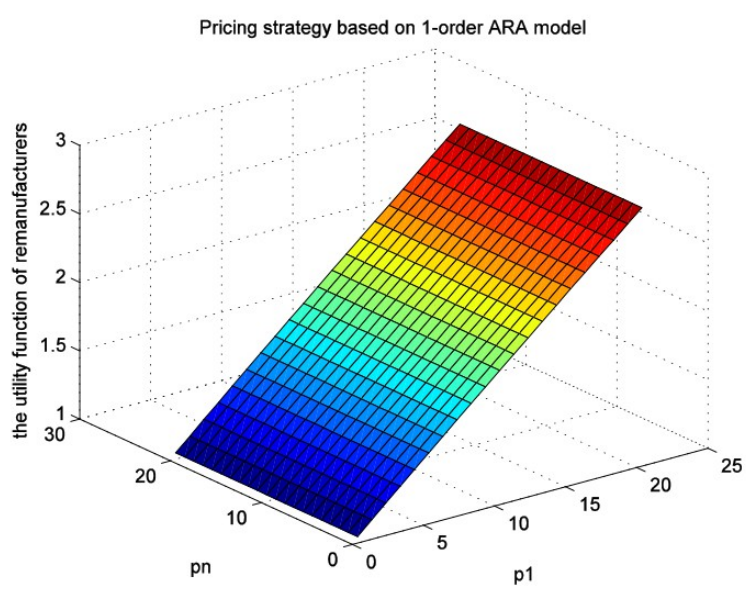

Figure 4. The classical remanufacturers' pricing strategy

Observing the Figure 3 and Figure 4, we have sound reason to say that the remanufacturers' pricing strategy based on 1-order ARA model is better than the classical pricing strategy, since the optimal utility function value of remanufacturers is bigger than the classical model. In fact, the unit production cost is not fixed but rather changed. Production technology and process improve cause the cost to change. Similar to OEM, as for remanufacturers, they have no way to know exactly the unit production cost. Consequently, remanufacturers have more disadvantages if they use the classical pricing strategy than they use remanufacturers' 1 -order ARA model. Through numerical simulation, we can achieve concordant conclusion.

\section{Conclusion}

In Stackelberg model, we suppose that OEMs know the opponent's pricing strategy. However, with the development of remanufacturing industry shakes OEMs' monopoly position and make remanufacturers become stronger and stronger, so, in fact, OEMs don't know the pricing strategy of remanufacturers. To come over this problem, we apply 1-order ARA model to the 
pricing strategies. We analyze the relation between OEMs and remanufacturers and build the opponent's pricing strategy model based on the game relationship between them. Ultimately, we gain the pricing strategy based on the opponents' pricing strategy model. Since the opponents will make a rational decision rather than make a random decision, the pricing strategies based on 1-order ARA model are more practical than the classical model. From the results of the numerical simulation, we have sound reason to state this conclusion.

In particular, on the one hand, the rate of recovery changes because of development of remanufacturing industry, improvement of new machines, disassemble-ability or other un-predicted reasons. As for OEMs, it is impossible to accurately know the rate of recovery. So, OEMs don't know the exactly pricing strategies of remanufacturers. Hence, the OEM's 1-oreder ARA model is more practical than the classical Stackelberg model and has advantage over the classical pricing strategies in profit. On the other hand, the unit production cost is not fixed but rather changed. Production technology and process improvement causes this cost to change. Similar to OEM, as for remanufacturers, they have no way to know exactly the unit production cost. Consequently, remanufacturers have more disadvantages if they use the classical pricing strategy than they use remanufacturers' 1-order ARA model.

In general, the research on application of ARA implies that we can get more actual results with this kind of modern risk analysis method and ARA can be extensively in pricing strategies of supply chain. Moreover, the thought and method of building ARA model can be widely applied to other strategies in all kinds of economic field, such as investing strategy, the problems about auction, bidding strategies, and so on.

\section{Further Research}

In this article, we only consider that 1-order ARA model as for parameter c. In fact, other parameters are uncertain rather than fixed numbers. In later research, we will explore that ARA model as for other parameters, such as $w_{i}, c_{i}, \beta, \gamma$, and so on. Moreover, we study high-order adversarial risk analysis model to the problems about pricing strategy and think about application of prospect theory in order to make the research results be more practical value. Furthermore, in this paper, some results and analysis methods can be applied to other pricing strategies of supply chain and other economic field.

\section{Acknowledgments}

This study was supported by National Natural Science Foundation of China (Grant Nos.10771054 and 71201051), the Doctor Researching Foundation of Hunan Normal University (Grant No. 2014BQ11), Philosophy and Social Science Fund Project of Hunan Province (No.14YBA264), Young Talents Training Plan of Hunan Normal University (2014YX04) and Natural Science Foundation of Zhejiang Province (Grant No. Y6100810). 


\section{References}

Agrawal, V., Atasu, A., \& Ittersum, K.V. (2010). The Effect of Remanufacturing on the Perceived Value of New Products. Working paper.

Akerlof, G.A. (1970). The market for "lemons": Quality uncertainty and the market mechanism. The quarterly journal of economics, 84(3), 488-500.

http://dx.doi.org/10.2307/1879431

Akerlof, G.A. (2002). Behavioral macroeconomics and macroeconomic behavior. The American Economic Review, 92(3), 411-433. http://dx.doi.org/10.1257/00028280260136192

Akerlof, G.A., \& Dickens, W.T. (1982). The economic consequences of cognitive dissonance. The American economic review, 72(3), 307-319.

Atasu, A, \& Wassenhove, L.N.V. (2008). Remanufacturing as a Marketing Strategy. Management Science, 54(10), 1731-1746. http://dx.doi.org/10.1287/mnsc.1080.0893

Atasu, A., Guide, V.D.R. Jr., \& Wassenhove, L.N.V. (2008). Product Reuse Economics in ClosedLoop Supply Chain Research. Production and Operations Management, 17(5), 483-496. http://dx.doi.org/10.3401/poms.1080.0051

Bond, E.W. (1982). A direct test of the "lemons" model: The marker for the used pickup trucks. The American economic review, 72(4), 836-840.

Brown, G., Carely, M., Salmeron, J., \& Wood, K. (2006) Defending critical infrastructure. Interfaces, 36, 530-544. http://dx.doi.org/10.1287/inte.1060.0252

Ferrer, G., \& Swaminathan, M.J. (2006). Managing new and remanufactured products. Management Science, 52(1), 15-26. http://dx.doi.org/10.1287/mnsc.1050.0465

Ferrer, G., \& Swaminathan, M.J. (2010). Managing new and differentiated remanufactured products. International Journal of Sustainable Engineering, 203(2), 370-379.

Heyes, A. (2000). Implementing environmental regulation: enforcement and compliance. Journal of regulatory economics, 17, 107-129. http://dx.doi.org/10.1023/A:1008157410380

Jaber, M.Y., \& El Saadany, A.M.A. (2009). The production, remanufacture and waste disposal model with lost sales. International Journal of Production Economics, 120(1), 115-124. http://dx.doi.org/10.1016/j.ijpe.2008.07.016

King, A., Burgess, S.C., Ijomah, W.J., \& McMahon, C.A. (2006). Reducing waste: Repair, recondition, remanufacture or recycle? Sustainable Development, 14(14), 257-267. http://dx.doi.org/10.1002/sd.271

Leontief, W. (1946). The pure theory of the guaranteed annual wage contract. The Journal of political Economy, 57(1), 76-79. http://dx.doi.org/10.1086/256311

Majumder, P., \& Groenevelt, H. (2001). Competition in remanufacturing. Production and Operations Management, 10(2), 125-141. http://dx.doi.org/10.1111/j.1937-5956.2001.tb00074.x

McAfee, R., \& McMillan, J. (1996a). Auctions and bidding. Journal of economic literature, 25, 699-738. 
McAfee, R., \& McMillan, J. (1996b). Competition and game theory. Journal of marketing research, 33, 263-267. http://dx.doi.org/10.2307/3152123

Mitra, S. (2007). Revenue management for remanufactured products. Omega, 35, 553-562. http://dx.doi.org/10.1016/j.omega.2005.10.003

Rios-Insua, D., Rios, J., \& Banks, D. (2009). Adversarial risk analysis. Journal of the American statistical association, 104(486), 841-854. http://dx.doi.org/10.1198/jasa.2009.0155

Rothkopf, M. (2007). Decision analysis: the right tool for auctions. Decision analysis, 4, 167172. http://dx.doi.org/10.1287/deca.1070.0097

Savaskan, C.R. (2004). Closed-Loop Supply Chain Models with Product Remanufacturing. Management Science, 50(2), 239-252. http://dx.doi.org/10.1287/mnsc.1030.0186

Spence, M. (1973). Market signalling. The quarterly journal of economics, 87(3), 355-374. http://dx.doi.org/10.2307/1882010

Velu, C., \& Iyer, S. (2008). The rationality of irrationality for managers: returns-based beliefs and the traveler's dilemma. Cambridge working papers in economics, 0826. Faculty of economics, University of Cambridge.

Webster, S., \& Mitra, S. (2007). Competitive strategy in remanufacturing and the impact of take-back laws. Journal of Operations Management, 25, 1123-1140.

http://dx.doi.org/10.1016/j.jom.2007.01.014

Winterfeldt, D.V., \& O'Sullivan, T.M. (2006). Should we protect commercial airplane against Surface-to-air missile attacks by terrorists. Decision analysis, 3, 63-75.

http://dx.doi.org/10.1287/deca.1060.0071

Wu, C.-H. (2013). OEM product design in a price competition with remanufactured product.

Omega, 41, 287-298. http://dx.doi.org/10.1016/j.omega.2012.04.004

Wu, C.-H. (2012a). Price and service competition between new and remanufactured products in a two-echelon supply chain. Int. J.Production Economics, 140, 496-507. http://dx.doi.org/10.1016/j.ijpe.2012.06.034

Wu, C.-H. (2012b). Product-design and pricing strategies with remanufacturing. European Journal of Operational Research, 222, 204-215. http://dx.doi.org/10.1016/j.ejor.2012.04.031

Yüksela, H. (2010). Design of automobile engines for remanufacture with quality function deployment. International Journal of Sustainable Engineering, 3(3), 170-180.

http://dx.doi.org/10.1080/19397038.2010.486046

Journal of Industrial Engineering and Management, 2015 (www.jiem.org)

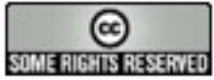

Article's contents are provided on a Attribution-Non Commercial 3.0 Creative commons license. Readers are allowed to copy, distribute and communicate article's contents, provided the author's and Journal of Industrial Engineering and Management's names are included. It must not be used for commercial purposes. To see the complete license contents, please visit http://creativecommons.org/licenses/by-nc/3.0/. 